\title{
Correspondence
}

Cerebrovascular Diseases

Cerebrovasc Dis 2011;32:194-195

DOI: $10.1159 / 000328664$

\section{Uncertainties in the Assessment of Cortical Flow by Perfusion-Weighted MRI in Acute Stroke}

\author{
Wolf-Dieter Heiss, Olivier Zaro Weber
}

Max Planck Institute for Neurological Research, Cologne, Germany

In a study of 145 acute ischemic stroke patients, Galinovic et al. [1] analyzed the validity of various parameters in perfusionweighted magnetic resonance imaging (PW-MRI) to predict the extent of final infarction. They conclude that: (1) volumes of perfusion deficit overestimate the final lesion size, (2) volumes of calculated critical perfusion values were significantly different between programs for calculating the same map and threshold, and (3) on a patient-to-patient basis, a rater significantly under- or overestimated the final lesion size. Based on these data, the authors concluded that no combination of software, map and threshold was able to give a reliable estimate of tissue fate for all patients, thereby severely questioning the wide acceptance of the application of MRI procedures to assess the 'penumbra' or to predict the final lesion size.

After the first reports of the use of perfusion-weighted MRI (PW-MRI) in critically perfused tissue to predict the extent of final infarctions $[2,3]$ and assess reperfusion after recanalization [4], several studies proved that the values for critically perfused tissue were dependant on the methods used for its calculation [5-7]. Due to intrinsic characteristics of these methods, PW-MRI was considered to be an unreliable tool to derive absolute values for cerebral blood flow [8], an assumption supported by a low correspondence of flow values determined by PW-MRI to those from quantitative measurements with positron emission tomography with ${ }^{15} \mathrm{O}$-labeled water in healthy volunteers [9] and patients after stroke $[10,11]$.

Two different limitations of PW-MRI might be responsible for the inaccuracies in the assessment of reliable flow values: the difficulties in accurately measuring the delay in tracer arrival, dispersion and transit in pathologically perfused tissue, and the difficulties in determining the arterial input function for the respective tissue volume. In most studies, the delay of tracer transit in the critical area is compared to the contralateral side using different procedures of analysis for the delay in bolus arrival [12]; after some corrections, these estimates may show some correlations to quantitative flow values [11, 13-15], and arrival delay has successfully been applied to predict outcome based on tissue at risk and response to reperfusion [16].

However, whereas non-deconvolved methods to assess the delay are useful to demonstrate effects of reperfusion due to recana- lization, they have limited value in assessing changes in blood flow due to improved collateral perfusion. This means that patients with regional hemodynamic delay due to occlusion or stenosis of the supplying arteries will have time-to-peak abnormalities due to the delay in arterial input, and changes in the perfusion within these areas usually cannot be detected accurately by determination of the delay in tracer input, which might not be affected in the territory around an occluded vessel, despite the fact that blood flow in the collaterals might actually be increased.

Deconvolution methods of the tracer transit including input functions may be a better option in these patients [5], but $\mathrm{T}_{\max }$ will mainly show the delay, so probably suffers from the same restrictions as, for example, time-to-peak - i.e. from the long way the blood has to take before reaching the regions around the territory around the occluded vessel. Non-time-domain parameters, applying delay-insensitive deconvolution methods [17], might be better suited to assess critical hypoperfusion in patients with large arterial occlusion [18], even though these measures are probably most commonly affected by the increased bolus dispersion taking place in the collaterals. However, these methods suffer from uncertainty in defining a reliable input function, which is often obtained from the neck or from the contralateral side [7]. These vessels yield an imprecise definition of the input function to determine collateral flow, which is important for the survival of tissue in the area surrounding an ischemic infarct, predicting the response to endovascular therapy [19], and is the target of treatment strategies beyond revascularization procedures. Since collateral blood supply is believed to be a key prognostic factor in acute stroke, existing methods for perfusion-weighted imaging map calculation and mismatch definition have to be optimized to improve the detection of penumbral collateral supply in the future.

\section{References}

1 Galinovic I, Ostwaldt A-C, Soemmer C, Bros H, Hotter B, Brunecker P, Schmidt WU, Jungehülsing J, Fiebach JB: Search for a map and threshold in perfusion MRI to accurately predict tissue fate: a protocol for assessing lesion growth in patients with persistent vessel occlusion. Cerebrovasc Dis 2011;32:186-193.

$\checkmark 2$ Rosen BR, Belliveau JW, Vevea JM, Brady TJ: Perfusion imaging with NMR contrast agents. Magn Reson Med 1990;14:249-265.

3 Baird AE, Warach S: Magnetic resonance imaging of acute stroke. J Cereb Blood Flow Metab 1998;18:583-609.

4 Kidwell CS, Saver JL, Mattiello J, et al: Thrombolytic reversal of acute human cerebral ischemic injury shown by diffusion/perfusion magnetic resonance imaging. Ann Neurol 2000;47:462-469.

5 Yamada $\mathrm{K}, \mathrm{Wu} \mathrm{O}$, Gonzalez RG, et al: Magnetic resonance perfusionweighted imaging of acute cerebral infarction: effect of the calculation methods and underlying vasculopathy. Stroke 2002;33:87-94.

6 Kane I, Carpenter T, Chappell F, et al: Comparison of 10 different magnetic resonance perfusion imaging processing methods in acute ischemic stroke: effect on lesion size, proportion of patients with diffusion/ perfusion mismatch, clinical scores, and radiologic outcomes. Stroke 2007;38:3158-3164.

\section{KARGER}

Fax +41613061234 E-Mail karger@karger.ch www.karger.com (c) 2011 S. Karger AG, Basel

$1015-9770 / 11 / 0322-0194 \$ 38.00 / 0$ 
7 Christensen S, Mouridsen K, Wu O, et al: Comparison of 10 perfusion MRI parameters in 97 sub-6-hour stroke patients using voxel-based receiver operating characteristics analysis. Stroke 2009;40:2055-2061.

8 Calamante F, Gadian DG, Connelly A: Quantification of perfusion using bolus tracking magnetic resonance imaging in stroke: assumptions, limitations, and potential implications for clinical use. Stroke 2002;33 1146-1151.

-9 Ibaraki M, Shimosegawa E, Toyoshima H, et al: Effect of regional tracer delay on CBF in healthy subjects measured with dynamic susceptibility contrast-enhanced MRI: comparison with ${ }^{15} \mathrm{O}$-PET. Magn Reson Med Sci 2005;4:27-34.

10 Sobesky J, Weber OZ, Lehnhardt FG, et al: Which time-to-peak threshold best identifies penumbral flow? Stroke 2004;35:2843-2847.

11 Takasawa M, Jones PS, Guadagno JV, et al: How reliable is perfusion $\mathrm{MR}$ in acute stroke? Validation and determination of the penumbra threshold against quantitative PET. Stroke 2008;39:870-877.

12 Davis SM, Donnan GA, Butcher KS, Parsons M: Selection of thrombolytic therapy beyond $3 \mathrm{~h}$ using magnetic resonance imaging. Curr Opin Neurol 2005;18:47-52.

13 Olivot JM, Mlynash M, Zaharchuk G, et al: Perfusion MRI ( $\mathrm{T}_{\max }$ and MTT) correlation with xenon CT cerebral blood flow in stroke patients. Neurology 2009;72:1140-1145.

14 Carrera E, Jones PS, Iglesias S, et al: The vascular mean transit time: a surrogate for the penumbra flow threshold? J Cereb Blood Flow Metab 2011;31:1027-1035.

15 Zaro-Weber O, Moeller-Hartmann W, Heiss WD, Sobesky J: A simple positron emission tomography-based calibration for perfusion-weighted magnetic resonance maps to optimize penumbral flow detection in acute stroke. Stroke 2010;41:1939-1945.
16 Albers GW, Thijs VN, Wechsler L, et al: Magnetic resonance imaging profiles predict clinical response to early reperfusion: the Diffusion and Perfusion Imaging Evaluation for Understanding Stroke Evolution (DEFUSE) study. Ann Neurol 2006;60:508-517.

17 Wu O, Ostergaard L, Weisskoff RM, Benner T, Rosen BR, Sorensen AG: Tracer arrival timing-insensitive technique for estimating flow in $\mathrm{MR}$ perfusion-weighted imaging using singular value decomposition with a block-circulant deconvolution matrix. Magn Reson Med 2003;50: 164-174.

18 Kim SJ, Seok JM, Bang OY, et al: MR mismatch profiles in patients with intracranial atherosclerotic stroke: a comprehensive approach comparing stroke subtypes. J Cereb Blood Flow Metab 2009;29:1138-1145.

19 Bang OY, Saver JL, Kim SJ, et al: Collateral Flow Predicts Response to Endovascular Therapy for Acute Ischemic Stroke. Stroke 2011;42:693699.

Wolf-Dieter Heiss

Max Planck Institute for Neurological Research

Gleueler Strasse 50

DE-50931 Cologne (Germany)

Tel.+492214726 220, E-Mail wdh@nf.mpg.de 